\title{
HOW DO COGNITIVE AND AFFECTIVE TRUST IMPACT PROCESS-OUTCOME INTERACTION?
}

\author{
XUAN-NA WU \\ Capital Normal University \\ XUE WU \\ Peking University \\ WEI WANG \\ Chinese Academy of Sciences
}

\begin{abstract}
Procedural justice interacts with outcome favorability to influence people's beliefs and behaviors. However, different patterns of process-outcome interaction have been observed. In this study, we proposed that cognitive trust in authority and affective trust in authority would determine the pattern of process-outcome interaction in the field of public policy. A scenario designed to assess acceptance of public policy was used to examine our hypotheses. Participants were 373 Chinese undergraduate students. Results showed that cognitive trust moderated the process-outcome interaction, but affective trust did not. When participants had strong cognitive trust in authority, procedural justice reduced the negative effect of an unfavorable outcome (low-low interactive pattern); when participants had little cognitive trust in authority, procedural justice heightened the positive effect of a favorable outcome (high-high interactive pattern). The implications of our findings and possible avenues to explore in future research are discussed.
\end{abstract}

Keywords: procedural justice, outcome favorability, cognitive trust in authority, affective trust in authority, acceptance of public policy.

Xuan-Na Wu, Key Laboratory of Learning and Cognition, Department of Psychology, Capital Normal University; Xue Wu, School of Nursing, Peking University; Wei Wang, Institute of Psychology, Chinese Academy of Sciences.

This study was funded by the Natural Science Foundation of China (71401113).

Correspondence concerning this article should be addressed to: Xuan-Na Wu, Beijing Key Laboratory of Learning and Cognition, Department of Psychology, Capital Normal University, No. 105 Xisanhuan Beilu, Haidian, Beijing 100048, People's Republic of China. Email: wuxn@ cnu.edu.cn 
Procedural justice is an important factor in people's acceptance of public policy. It refers to the perceived fairness of procedures used to make allocation decisions (Tyler, 1988). The concept of procedural justice came from organizational justice (e.g., Leung, Tong, \& Lind, 2007). Organizational justice was studied in the field of organizational management and individual-level analysis (e.g., De Cremer et al., 2010); however, some procedures are primarily concerned with social groups rather than with specific individuals, and thus procedural justice can involve a macro perspective (Tyler, Boeckmann, Smith, \& Huo, 1997). For example, fair decisions, such as public policy decisions, (e.g., Leung et al., 2007) and layoff decisions in a workplace (e.g., Brockner et al., 2004) can affect a group of people. Moreover, in several studies the results have shown that people's perceptions of procedural justice are positively associated with their making a positive evaluation of the person or persons in authority (Leung et al., 2007; Wu \& Wang, 2013), of political trust (Ulbig, 2008), and of public decision acceptance (Chen \& Zhao, 2013; Leung et al., 2007; Ulbig, 2008). In addition, people are more likely to accept a policy when the policy outcome is favorable for them. In a large number of theories and studies it has also been shown that procedural justice often interacts with outcome favorability (e.g., Rolland \& Steiner, 2007; Wu \& $\mathrm{Wu}, 2015)$. Procedural justice can reduce the negative effect of an unfavorable outcome (Kwong \& Leung, 2002), and a policy gains the least acceptance when the procedure is unfair and the outcome unfavorable (Brockner \& Wiesenfeld, 1996; low-low interactive pattern). This well-known interaction pattern between procedural justice and outcome favorability is also called the compensatory effect of procedural justice (Kwong \& Leung, 2002; see Figure 1).

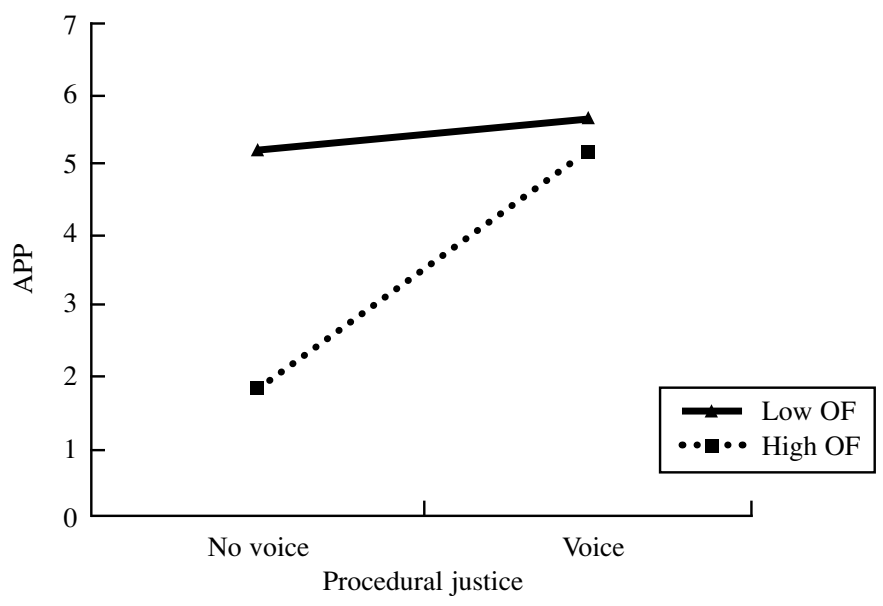

Figure 1. Interaction of procedural justice, and outcome favorability (low-low effect). Note . APP = acceptance of public policy, $\mathrm{OF}=$ outcome favorability. 
The interaction pattern depicted in Figure 1 was formerly considered to be very robust and general, because Brockner and Wiesenfeld (1996) examined the results of many studies and concluded that an unfavorable outcome together with an unfair procedure produced very negative responses in those affected by the decision of the authority. However, in several studies, the researchers did not find this interaction occurring (e.g., Dipboye \& de Pontbriand, 1981), and in some studies the results even showed that, under certain conditions, the interaction between procedure and outcome formed a pattern opposite to that shown in Figure 1.

In Figure 2, the pattern of a combination of a fair procedure and a fair outcome produce a very positive response (Lin, Che, \& Leung, 2009; high-high interactive pattern). Given the different forms of the process-outcome interaction reported in previous research, it is important to clarify the form this interaction takes, specifically, when it has a low-low effect and when it has a high-high effect.

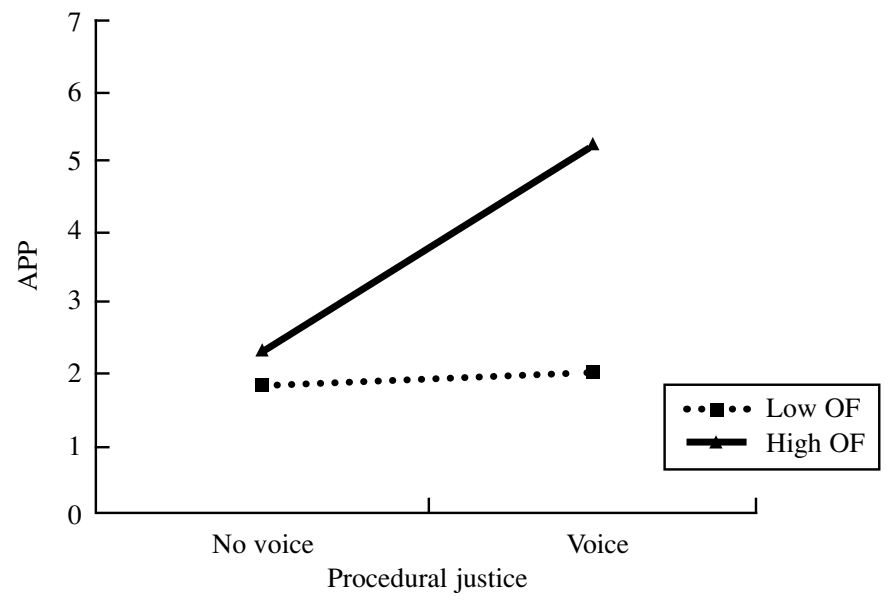

Figure 2. Interaction of procedural justice, and outcome favorability (high-high effect). Note. $\mathrm{APP}=$ acceptance of public policy, $\mathrm{OF}=$ outcome favorability.

Previous researchers have shown that the interaction between procedural justice and outcome favorability is moderated by other factors, such as leader morality (Lin et al., 2009), the relationship between subordinates and the people in authority (Kwong \& Leung, 2002), and uncertainty about one's position in the organization (De Cremer et al., 2010). Continuing with this line of work, we examined the moderating roles of cognitive trust in authority and affective trust in authority in the process-outcome interaction. 


\section{Organizing Framework and Hypotheses}

Trust is a complex and multidimensional mental state (McAllister, 1995) that reflects the level of confidence an individual has in another to act in a fair, ethical, and predictable manner (Luhmann, 1979). Rousseau, Sitkin, Burt, and Camerer (1998) integrated the characteristics of various disciplines, and defined trust as people's willingness to accept vulnerability based on positive expectations of the other party's intention or behaviors. McAllister (1995) conceptualized trust as having cognitive and affective dimensions. Cognitive trust is based on the individual's evaluation of other people's ability, predictability, and reliability (Mayer, Davis, \& Schoorman, 1995). Affective trust comes from people's emotional connection to the other person (McAllister, 1995). In this study, we used fairness heuristic theory (Lind, 2001) and social judgment theory (Sherif \& Hovland, 1961) and hypothesized that people's cognitive trust and affective trust in the decision-making authority would dictate the form of process-outcome interaction.

In fairness heuristic theory it is argued that people are willing to obey the decision made by a person or persons in authority, but are often afraid of being exploited and used. Accordingly, people will first enter a phase in which they judge whether or not the authority can be trusted. If those in authority make decisions that are perceived by subordinates as fair and that have a favorable for the subordinate group, then the subordinates tend to think that those in authority can be trusted (Kramer \& Tyler, 1996). In the next phase, people will use their previous judgment to guide their attitudes and behaviors (the use phase). If people now face a decision related to fairness, this information will be assimilated into their current judgment. If these events or experiences differ greatly from the person's initial judgment on trust, the current events/experiences cannot be assimilated into the existing judgment. People may return to the initial (judgment) phase (Lind, 2001), in order to reexamine and revise their beliefs about fairness. As Lind demonstrated, if the experiences diverge only slightly from expectations formed when the person made his or her initial judgment, they will be explained away and assimilated into the existing judgment of trust (p. 79). Thus, when people trust authority, as long as they perceive the procedure as fair or the outcome as favorable, the assimilation process occurs and consequently subordinates will show a positive attitude toward the decision making of those in authority. However, when the procedure is not just and the outcome is unfavorable, conflict occurs and people will react negatively. For example, when people have formed a judgement of trust in authority, they will have positive expectations of the authority's intentions or behavior. They will think that the person/people in authority can give them fair procedures and favorable or fair outcomes. So if those in authority initiate unfair procedures that lead to unfavorable outcomes, 
the negative experience will conflict with the previous positive expectations that the people have formed about those in authority. As a result, as argued in social judgment theory and the fairness heuristic theory, people will behave negatively.

On the contrary, when people distrust those in authority, an assimilation process occurs when the procedure is unfair or the outcome is unfavorable, and people will have a negative attitude toward the decision making of those in authority. However, when both procedural justice and outcome favorability are positive, conflict occurs, and people will behave positively. For example, when people do not trust the person/people in authority, they will have negative expectations of their intentions or behavior. They will think that those in authority will not give them fair procedures or favorable or fair outcomes. Thus, if the person in authority gives them fair procedures together with favorable outcomes, this positive experience will conflict with the subordinates' previous negative expectations about the person in authority. As a result, according to social judgment theory and the fairness heuristic theory, people will behave positively.

In addition, in social judgment theory (e.g., Sherif \& Hovland, 1961) it has been shown that people's reactions to a superior's decision are often in line with previous expectations (the consistency effect). If the subordinates initially have positive expectations, ultimately, they will behave positively. If their actual experiences are greatly different from their expectations, people are less likely to react in line with previous expectations and are more likely to respond in a way that is consistent with their actual experiences. People's trust in authority essentially creates in them an expectation of how the authority is likely to behave toward them (Mayer et al., 1995). The expectations of the subordinates may involve not only outcome information but also procedural information. Therefore, we proposed that when both actual procedures and outcomes clearly diverge from people's expectations, the contrast effect would appear; when only either procedures or outcomes diverge from the people's expectations, the consistency effect would appear. Therefore, our hypotheses were as follows:

Hypothesis 1a: People's acceptance of public policy will be affected by the three-way interaction effect of cognitive trust in authority, procedural justice, and outcome favorability.

Hypothesis 1b: When cognitive trust is strong, procedural justice will reduce the negative effect of an unfavorable outcome, and policy acceptance will be lowest when both procedural justice and outcome favorability are negative (the low-low pattern shown in Figure 1).

Hypothesis 1c: When cognitive trust is weak, procedural justice will heighten the positive effect of a favorable outcome, and policy acceptance will be greatest when both procedural justice and outcome favorability are positive (the highhigh pattern shown in Figure 2). 
Hypothesis 2a: People's acceptance of public policy will be affected by the three-way interaction effect of affective trust in authority, procedural justice, and outcome favorability.

Hypothesis 2b: When affective trust is strong, procedural justice will reduce the negative effect of an unfavorable outcome, and policy acceptance will be lowest when both procedural justice and outcome favorability are negative (the low-low pattern shown in Figure 1).

Hypothesis 2c: When affective trust is weak, procedural justice will increase the positive effect of a favorable outcome, and policy acceptance will be greatest when both procedural justice and outcome favorability are positive (the highhigh pattern shown in Figure 2).

\section{Method}

\section{Participants and Design}

Participants were 373 undergraduate students $($ men $=32 \%$, women $=68 \%)$ at a large university in Beijing, China. The age range of the students was from 18 to 22 years $(M=20.46 ; S D=1.09)$. Students in a class in psychology were recruited on a voluntary basis and were given a gift of 10 RMB (1.53 USD) for compensation. This study was a 2 (cognitive trust in authority: high vs. low) $\times$ 2 (affective trust in authority: high vs. low) $\times 2$ (procedural justice: voice vs. no voice) $\times 2$ (outcome favorability: high vs. low) between-participants design. Participants were randomly assigned to one of the 16 groups that formed the two-level four-factor design, with 23 or 24 participants in each group.

\section{Procedure}

On arrival at the laboratory, participants were asked whether or not they were willing to participate in a paper-and-pencil study. When we had obtained informed consent from the participants, they then read a scenario involving household registration policymaking. Household registration refers to permanent residency in China, and is closely linked to provision of social welfare. For instance, once people have obtained household registration, they are entitled to many benefits of public service, children's education and so forth.

In our study participants were asked to imagine that they were the target person for household registration. The scenario was as follows:

"You are a registered agricultural resident of City D. At present, there are two types of registration in City D: agricultural registration and nonagricultural registration. City D is reforming its residency registration system."

Then, participants read more material in which the four independent variables were manipulated. The variables of cognitive trust and affective trust were presented first. In order to avoid the order effect, the material for cognitive trust and affective trust was presented in random order. 
Manipulation of cognitive trust in authority. In the high-trust condition, participants were told that the administrative body in City D had sufficient operational and administrative capacity and could satisfy the public in terms of urban management. In the low-trust condition, participants were told that the administrative body in City D did not have sufficient operational and administrative capacity and could not satisfy the public in terms of urban management.

Manipulation of affective trust in authority. In the high-trust condition, participants were told that administrative body in City D was very concerned about the quality of residents' life, would fully consider the interests of each resident, and would not exploit residents for the private gain of the administrators. In the low-trust condition, participants were told that administrative body of City D was not concerned about the quality of residents' life, would not consider the interests of each resident, and would exploit residents for the private gain of the administrators.

Manipulation of procedural justice. In the voice condition, participants were told that the administrative body of City D had opened a number of channels to allow people to give them advice. In the no-voice condition, participants were told that the administrative body of City D did not have any channels to allow people to give them advice.

Manipulation of outcome favorability. In the high outcome-favorability condition, participants were told that the administrative body of City D had canceled the agricultural/nonagricultural division and had unified the urban and rural registration systems. Under the new system, as a person previously registered as an agricultural resident, the participant would now not only enjoy all the rights of those with urban accounts but also the exclusive benefits of those with agricultural accounts.

In the low outcome-favorability condition, participants were told that the administrative body of City D had canceled the agricultural/nonagricultural division and unified the urban and rural registration systems. Under the new system, as a person previously registered as an agricultural resident, the participant would now enjoy fewer benefits than before. Because of the cancellation of agricultural accounts, some benefits exclusive to those with agricultural accounts were also canceled.

\section{Measures}

Participants were asked to answer questions for a manipulation check and outcomes, all of which were rated on a 7-point scale ranging from $(1=$ disagree very much $)$ to $(7=$ agree very much $)$. To confirm whether or not the participants had involved themselves in the scenario, they were asked about some details of the scenario such as: "Did the City D administrators solicit 
public opinion when enacting the household registration policy?" To assess cognitive trust in authority, participants were asked to what extent they trusted the administrative body of City D cognitively with the question: "Do you trust that the administrators of City D have sufficient operational and administrative capacity?" To assess affective trust in authority, participants were asked to what extent they trusted the administration body of City D affectively as follows: "Do you trust that the administrators of City D fully consider the interests of each resident?" To assess procedural justice, participants were asked to what extent they regarded the public policymaking procedure as fair. To assess outcome favorability, participants were asked to what extent the outcome would benefit them. Acceptance of public policy was measured with three items adapted from those used in the study by Leung et al. (2007). A sample item is: "As a resident of City D, do you approve of the reform of the household registration policy?"

\section{Data Analysis}

Analysis of four-factor between-subjects variance (ANOVA) was performed with the research data.

\section{Results}

\section{Manipulation Checks}

Results of ANOVA on the procedural justice manipulation check revealed that our manipulation of trust in authorities was successful. As expected, participants in the voice condition reported higher procedural justice than did those in the no-voice condition ( $M=4.90$ vs. 2.44 , respectively), $F(1,357)=752.73, p<$ $.001, \eta^{2}=.68$. Participants in the high cognitive-trust condition reported stronger cognitive trust than did those in the low cognitive-trust condition $(M=5.30$ vs. 2.48 , respectively), $F(1,357)=1032.66, p<.001, \eta^{2}=.74$. Participants in the high affective-trust condition reported stronger affective trust than did those in the low affective-trust condition ( $M=5.15$ vs. 2.71 , respectively), $F(1,357)$ $=640.75, p<.001, \eta^{2}=.64$. The outcome favorability manipulation was also successfully induced: ( $M=5.45$ vs. 2.34 , respectively), $F(1,357)=1330.82, p$ $<.001, \eta^{2}=.75$.

\section{Hypotheses Tests}

A $2 \times 2 \times 2 \times 2$ ANOVA was performed on acceptance of public policy. The results of the analysis revealed a positive main effect of procedural justice, $F(1,357)=38.92, p<.001, \eta^{2}=.10$, cognitive trust, $F(1,357)=39.87, p$ $<.001, \eta^{2}=.10$, affective trust, $F(1,357)=14.19, p<.001, \eta^{2}=.04$, and outcome favorability, $F(1,357)=1332.516, p<.001, \eta^{2}=.79$. In order to test our hypotheses, it was important to test the 2 three-way interactions. The 
results of the analysis revealed a significant procedural justice $\times$ outcome favorability $\times$ cognitive trust interaction, $F(2,357)=12.69, p<.001, \eta^{2}=.03$. Thus, Hypothesis 1a was supported. However, the procedural justice $\times$ outcome favorability $\times$ affective trust interaction was nonsignificant $(F<1)$. Therefore, Hypotheses $2 \mathrm{a}, 2 \mathrm{~b}$, and $2 \mathrm{c}$ were not supported.

To analyze the three-way interaction, simple interaction effect analyses and simple main effect analyses were conducted. As depicted in Figure 3, in the high cognitive-trust condition a significant procedural justice $\times$ outcome favorability interaction emerged, $F(1,179)=4.22, p<.05, \eta^{2}=.02$. High procedural justice weakened the negative effect of unfavorable outcome. Analysis of simple main effects showed that procedural justice had a significantly positive effect when the outcome was not favorable, $F(1,89)=12.70, p<.01, \eta^{2}=.13$, but not when the outcome was favorable, $F(1,90)=.90, n s, \eta^{2}=.01$. Policy acceptance was lowest when both procedural justice and outcome favorability were negative. Therefore, Hypothesis $1 \mathrm{~b}$ was supported. As depicted in Figure 4, in the low cognitive-trust condition a different and significant procedural justice $\times$ outcome favorability interaction emerged, $F(1,178)=8.89, p<.01, \eta^{2}=.05$. High procedural justice heightened the positive effect of favorable outcome. Analysis of simple main effects showed that procedural justice had a significantly positive effect when the outcome was favorable, $F(1,89)=32.25, p<.001, \eta^{2}=.27$, but not when the outcome was not favorable, $F(1,90)=3.62, n s, \eta^{2}=.04$. Policy acceptance was greatest when both procedural justice and outcome favorability were positive. Therefore, Hypothesis 1c was supported.

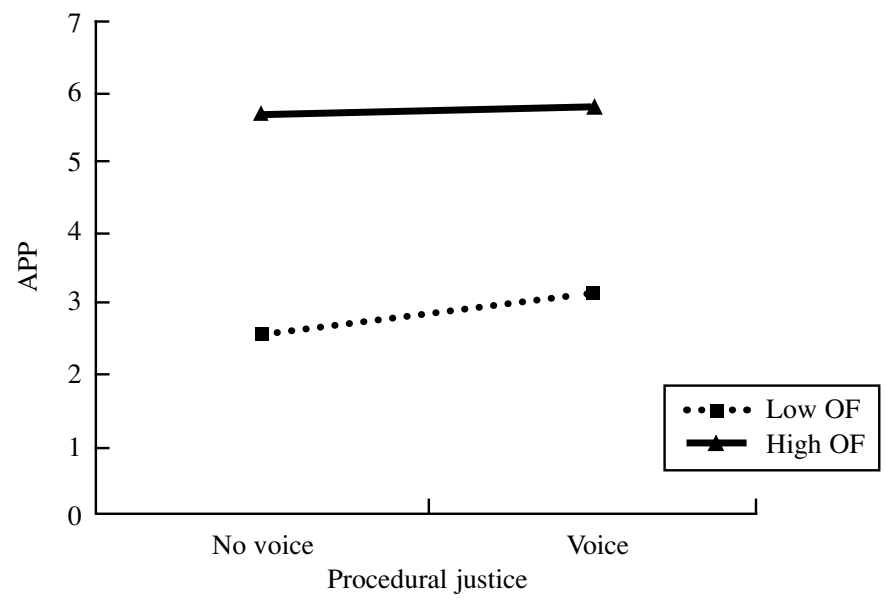

Figure 3. Interaction of procedural justice and outcome favorability when cognitive trust in authority is strong.

Note. $\mathrm{APP}=$ acceptance of public policy, $\mathrm{OF}=$ outcome favorability. 


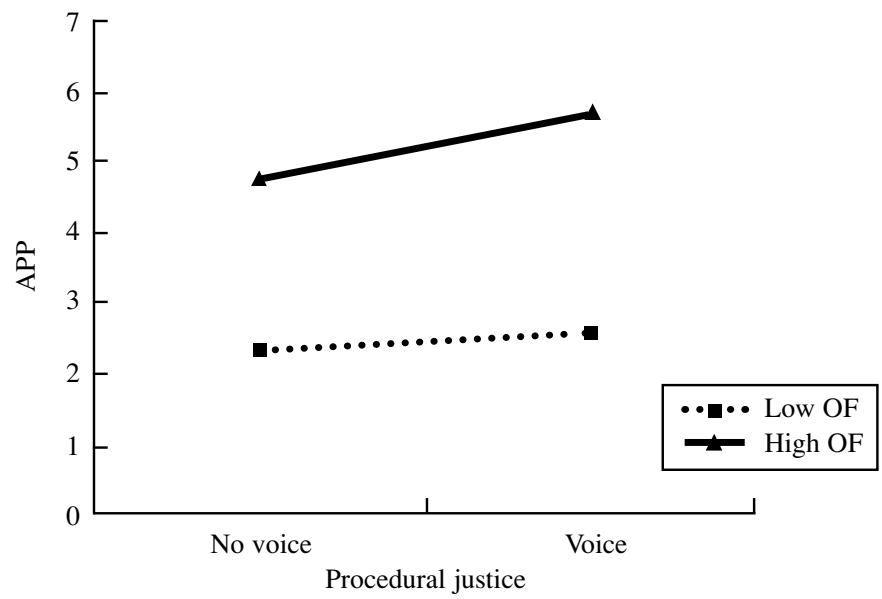

Figure 4. Interaction of procedural justice and outcome favorability when cognitive trust in authority is weak.

Note. APP = acceptance of public policy, $\mathrm{OF}=$ outcome favorability.

\section{Discussion}

The results of our study partially supported our hypotheses. Specifically, a three-way interaction effect of cognitive trust in authority, procedural justice, and outcome favorability on people's acceptance of public policy was significant. When cognitive trust was strong, acceptance of public policy was particularly low when the outcome for participants was unfavorable together with an unfair procedure. When cognitive trust was weak, acceptance of public policy was particularly high when the outcome was favorable for participants together with a fair procedure. The results indicated that the level of cognitive trust could dictate the pattern of process-outcome interaction. When people trusted those in authority, based on their competence and reliability, procedural justice reduced the negative effect of an unfavorable outcome. When people distrusted those in authority, based on their competence and reliability, a different pattern emerged in the process-outcome interaction. Procedural justice heightened the positive effect of a favorable outcome.

We did not find any moderating effect of affective trust on process-outcome interaction, nor did affective trust dictate the form of procedural justice and outcome favorability as we had expected. This latter finding leads to an interesting discussion. According to fairness heuristic theory, when both procedure and outcome clearly diverge from people's expectations, they cannot be assimilated into the existing judgment. People may be jolted back to reexamining and 
revising their judgment related to fairness (Lind, 2001), so that their expectation formed from their affective trust of those in authority has to be revised or altered. However, different from cognitive trust, affective trust is grounded in an individual's attributions concerning others' motives for their behaviors (McAllister, 1995). Once an evaluation is formed it is not easily revoked (Zajonc, 1980). Ascribed motives are taken as permanent and are unquestioned, even in the face of contradictory evidence (McAllister, 1995). Transgressions are discounted in advance or explained away. Thus, people are less likely to revise their existing expectations; instead they are more likely to respond according to their existing expectations. Therefore, affective trust may not dictate the form of procedural justice and outcome favorability.

\section{Theoretical and Practical Implications}

In the present research we have contributed to theory and practice in regard to justice. The compensatory effect of procedural justice was formerly thought to be very robust and general after Brockner and Wiesenfeld (1996) examined the findings in many different studies and reached a conclusion that an unfair procedure together with an unfavorable outcome produced very negative responses in those receiving this treatment. Since then there have been several studies conducted in which this interaction effect has not been present (e.g., Dipboye \& Pontbriand, 1981), and in some studies it has even been shown that under certain conditions the interaction between procedure and outcome takes a completely different form. The present findings help clarify when and how procedural justice interacts with outcome favorability to affect people's attitudes and behaviors. Cognitive trust impacts the pattern of this interaction. Moreover, our findings suggest a theoretical question that we find interesting about how cognitive and affective trust relate to the interaction between process and outcome. Prior researchers have reported finding that trust mediates the process-outcome interaction. In the present study, cognitive trust in those in authority also moderated the process-outcome interaction. Thus, it will be necessary to explore when trust in authority operates as moderator or mediator and the different influences of the two types of trust. In practical terms, public policy cannot always be favorable to all residents. Political authorities should put effort into improving the amount of work they can do, and their administrative capacity, to ensure people's high cognitive trust. Only in this way can procedural justice reduce the negative influence of an unfavorable outcome. Also, the present findings provide hope to those in authority who do not have the trust of the people and who are trying to improve those people's acceptance of policies. If they can deliver fair procedures and favorable outcomes, they may be able to break the vicious cycle between people's lack of trust in them and the acceptance of their policies (Bianchi et al., 2015). 


\section{Limitations and Future Directions}

A limitation in this study was the use of a scenario. This method is often used in justice-related studies to induce causal results that are based on experiments. However, when a scenario is used, the researcher is dependent on people's imagination. It is necessary to replicate the three-way interaction we predicted in experiments and in real-life settings. Second, we studied only one element of procedural justice, namely, voice. To test our prediction, future researchers should use different procedural justice manipulations, such as whether or not those in authority treat all people the same. Finally, the dependent variable, namely acceptance of public policy, was intentional or attitudinal, not behavioral. In future research behavioral measures should be incorporated to make the evidence more convincing.

\section{References}

Bianchi, E. C., Brockner, J., van den Bos, K., Seifert, M., Moon, H., van Dijke, M., \& De Cremer, D. (2015). Trust in decision-making authorities dictates the form of the interactive relationship between outcome fairness and procedural fairness. Personality and Social Psychology Bulletin, 41, 19-34. http://doi.org/44t

Brockner, J., Spreitzer, G., Mishra, A., Hochwarter, W., Pepper, L., \& Weinberg, J. (2004). Perceived control as an antidote to the negative effects of layoffs on survivors' organizational commitment and job performance. Administrative Science Quarterly, 49, 76-100.

Brockner, J., \& Wiesenfeld, B. M. (1996). An integrative framework for explaining reactions to decisions: Interactive effects of outcomes and procedures. Psychological Bulletin, 120, 189-208. http://doi.org/bwfp73

Chen, X. J., \& Zhao, J. H. (2013). Bidding to drive: Car license auction policy in Shanghai and its public acceptance. Transport Policy, 27, 39-52. http://doi.org/bf67

De Cremer, D., Brockner, J., Fishman, A., van Dijke, M., van Olffen, W., \& Mayer, D. M. (2010). When do procedural fairness and outcome fairness interact to influence employees' work attitudes and behaviors? The moderating effect of uncertainty. Journal of Applied Psychology, 95, 291-304. http://doi.org/dpp3bh

Dipboye, R. L., \& de Pontbriand, R. (1981). Correlates of employee reactions to performance appraisals and appraisal systems. Journal of Applied Psychology, 66, 248-251. http://doi.org/ c82x6q

Kramer, R. M., \& Tyler, T. R. (1996). Trust in organizations: Frontiers of theory and research. Thousand Oaks, CA: Sage.

Kwong, J. Y. Y., \& Leung, K. (2002). A moderator of the interaction effect of procedural justice and outcome favorability: Importance of the relationship. Organizational Behavior and Human Decision Processes, 87, 278-299. http://doi.org/bgq86m

Leung, K., Tong, K.-K., \& Lind, E. A. (2007). Realpolitik versus fair process: Moderating effects of group identification on acceptance of political decisions. Journal of Personality and Social Psychology, 92, 476-489. http://doi.org/c9jjdd

Lin, X.-W., Che, H.-S., \& Leung, K. (2009). The role of leader morality in the interaction effect of procedural justice and outcome favorability. Journal of Applied Social Psychology, 39, 1536-1561. http://doi.org/ckbwft 
Lind, E. A. (2001). Fairness heuristic theory: Justice judgments as pivotal cognitions in organizational relations. In J. Greenberg \& R. Cropanzano (Eds.), Advances in organizational justice (pp. 56-88). Palo Alto, CA: Stanford University Press.

Luhmann, N. (1979). Trust and power. Chichester, UK: Wiley.

Mayer, R. C., Davis, J. H., \& Schoorman, F. D. (1995). An integrative model of organizational trust. Academy of Management Review, 20, 709-734. http://doi.org/fs6wzz

McAllister, D. J. (1995). Affect- and cognition-based trust as foundations for interpersonal cooperation in organizations. Academy of Management Journal, 38, 24-59. http://doi.org/bsdqqf

Rolland, F., \& Steiner, D. D. (2007). Test-taker reactions to the selection process: Effects of outcome favorability, explanations, and voice on fairness perceptions. Journal of Applied Social Psychology, 37, 2800-2826. http://doi.org/cvmpmj

Rousseau, D. M., Sitkin, S. B., Burt, R. S., \& Camerer, C. (1998). Not so different after all: A crossdiscipline view of trust. Academy of Management Review, 23, 393-404. http://doi.org/ccr4xm

Sherif, M., \& Hovland, C. I. (1961). Social judgment: Assimilation and contrast effects in communication and attitude change. New Haven, CT: Yale University Press.

Tyler, T. R. (1988). What is procedural justice? Criteria used by citizens to assess the fairness of legal procedures. Law and Society Review, 22, 103-136. http://doi.org/fpx9c7

Tyler, T. R., Boeckmann, R. J., Smith, H. J., \& Huo, Y. J. (1997). Social justice in a diverse society. Boulder, CO: Westview Press.

Ulbig, S. G. (2008). Voice is not enough: The importance of influence in political trust and policy assessments. Public Opinion Quarterly, 72, 523-539. http://doi.org/fn725r

Wu, X.-N., \& Wang, E.-P. (2013). Outcome favorability as a boundary condition to voice effect on people's reactions to public policymaking. Journal of Applied Social Psychology, 43, 329-337. http://doi.org/bf68

Wu, X.-N., \& Wu, X. (2015). Do the compensatory effects of outcome and procedure on policy acceptance depend on trust in authority? Social Behavior and Personality: An international journal, 43, 1429-1440. http://doi.org/bf69

Zajonc. R. B. (1980). Feelings and thinking: Preferences need no inferences. American Psychologist, 35, 151-175. http://doi.org/d5h4dm 
Copyright of Social Behavior \& Personality: an international journal is the property of Society for Personality Research and its content may not be copied or emailed to multiple sites or posted to a listserv without the copyright holder's express written permission.

However, users may print, download, or email articles for individual use. 